\title{
PHASE II DRUG METABOLIZING ENZYMES
}

\author{
Petra Jancova $^{\mathrm{a} *}$, Pavel Anzenbacher ${ }^{\mathrm{b}}$, Eva Anzenbacherova ${ }^{\mathrm{a}}$
}

\begin{abstract}
a Department of Medical Chemistry and Biochemistry, Faculty of Medicine and Dentistry, Palacky University, Hnevotinska 3 , 77515 Olomouc, Czech Republic

${ }^{b}$ Department of Pharmacology, Faculty of Medicine and Dentistry, Palacky University, Hnevotinska 3, 77515 Olomouc E-mail: jancovapetra@seznam.cz
\end{abstract}

Received: March 29, 2010; Accepted: April 20, 2010

Key words: Phase II biotransformation/UDP-glucuronosyltransferases/Sulfotransferases, $N$-acetyltransferases/Glutathione S-transferases/Thiopurine S-methyl transferase/Catechol O-methyl transferase

Background. Phase II biotransformation reactions (also 'conjugation reactions') generally serve as a detoxifying step in drug metabolism. Phase II drug metabolising enzymes are mainly transferases. This review covers the major phase II enzymes: UDP-glucuronosyltransferases, sulfotransferases, N-acetyltransferases, glutathione S-transferases and methyltransferases (mainly thiopurine S-methyl transferase and catechol O-methyl transferase). The focus is on the presence of various forms, on tissue and cellular distribution, on the respective substrates, on genetic polymorphism and finally on the interspecies differences in these enzymes.

Methods and Results. A literature search using the following databases PubMed, Science Direct and EBSCO for the years, 1969-2010.

Conclusions. Phase II drug metabolizing enzymes play an important role in biotransformation of endogenous compounds and xenobiotics to more easily excretable forms as well as in the metabolic inactivation of pharmacologically active compounds. Reduced metabolising capacity of Phase II enzymes can lead to toxic effects of clinically used drugs. Gene polymorphism/ lack of these enzymes may often play a role in several forms of cancer.

\section{INTRODUCTION}

It is generally accepted that the biotransformation of substances foreign to the body (xenobiotics) including drugs is divided into phases I and II. Phase I reactions include transformation of a parent compound to more polar metabolite(s) by unmasking or de novo formation of functional groups (e.g. - $\mathrm{OH},-\mathrm{NH}_{2},-\mathrm{SH}$ ). Reactions include e.g. $\mathrm{N}$ - and $\mathrm{O}$-dealkylation, aliphatic and aromatic hydroxylation, $N$ - and $S$-oxidation, and deamination. The main enzymes in this phase are cytochromes P450 (CYPs) performing mainly hydroxylations and hence acting as monooxygenases, dioxygenases and hydrolases. The cytochromes $\mathrm{P} 450$ constitute a superfamily of heme enzymes responsible for the metabolism of xenobiotics and endobiotics. They are also involved in a variety of biosynthetic processes ${ }^{1}$.

Phase II enzymes play also an important role in the biotransformation of endogenous compounds and xenobiotics to more easily excretable forms as well as in the metabolic inactivation of pharmacologically active substances. The purpose of phase II biotransformation is to perform conjugating reactions. These include glucuronidation, sulfation, methylation, acetylation, glutathione and amino acid conjugation. In general, the respective conjugates are more hydrophilic than the parent compounds.

Phase II drug metabolizing enzymes are mostly transferases and include: UDP-glucuronosyltransferases (UGTs), sulfotransferases (SULTs), N-acetyltransferases
(NATs), glutathione S-transferases (GSTs) and various methyltransferases (mainly thiopurine S-methyl transferase (TPMT) and catechol O-methyl transferase $(\mathrm{COMT}))$. The participation of phase II drug metabolizing enzymes in the metabolism of clinically used drugs is shown in Fig. 1.

Phase II enzymes have attracted much less attention in clinical pharmacology than cytochromes $\mathrm{P} 450$ because drug interactions involving these enzymes are relatively

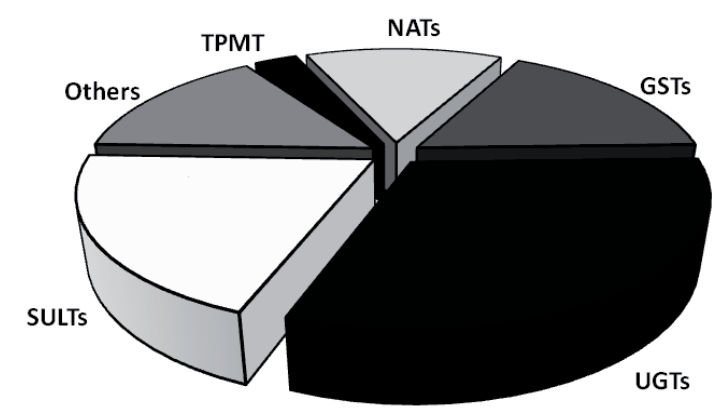

Fig. 1. Participation of major phase II enzymes in the metabolism of clinically used drugs.

UGTs, UDP-glucuronosyltransferases; SULTs, sulfotransferases; NATs, N-acetyltransferases; GSTs, glutathione S-transferases; TPMT, thiopurine S-methyltransferase. (According to Goodman and Gilman's manual of pharmacology and therapeutics (eleventh edition, 2007)). 
rare. Nevertheless, the reduced metabolising capacity of the phase II enzymes can lead to the manifestation of the toxic effects of clinical drugs. Although phase II reactions are generally detoxifying, the conjugates formed may also mediate adverse effects (e.g. conjugates acting as carriers for potentially carcinogenic compounds in the activation of benzylic alkohols, polycyclic aromatic hydrocarbons, aromatic hydroxylamines, hydroxamic acid and nitroalkanes by sulphotransferases) (ref. ${ }^{2}$ ).

There are also individual differences in metabolic response for both Phase I and Phase II enzymes. Further, both external (smoking, medication, nutrition and effects of the environment) and internal (age, sex, diseases and genetics) factors are known to influence phase II enzymes.

\section{UDP-GLUCURONOSYLTRANSFERASES}

(UGTs; EC 2.4.1.17)

UDP-glucuronosyltransferases are the key enzymes of the process known as glucuronidation. The formation of glucuronide conjugates is the most important detoxication pathway of the Phase II of drug metabolism in all vertebrates. In humans, approximately $40-70 \%$ of all clinical drugs are subjected to glucuronidation reactions metabolized by UGTs ${ }^{3}$. UGT enzymes are responsible for the metabolism of many xenobiotics (e.g. drugs, chemical carcinogens, environmental pollutants and dietary substances) and endobiotics (e.g. bilirubin, steroid hormones, thyroid hormones, bile acids and fat-soluble vitamins ) (ref. ${ }^{4,5}$ ).

The UGTs are a superfamily of membrane-bound enzymes catalyzing the formation of a chemical bond between a nucleophilic O-, N-, S-, or C-atom with uridine5 '-diphospho- $\alpha$-D-glucuronic acid (UDPGA). The glucuronic acid is in the $\alpha$-configuration at the $\mathrm{C} 1$ atom when bound to the coenzyme and the transfer occurs with an inversion of configuration. This reaction leads to formation of the respective $\beta$-D-glucuronides (Fig. 2) with easy elimination via bile or urine.

All UGT enzymes are capable of forming O-linked glucuronides. These can be formed through conjugation of UDPGA with aliphatic alcohols, phenols, carboxylic acids, thiols and amines (primary, secondary, tertiary) (ref. ${ }^{6}$ ).

\section{Forms of UGT, tissue and cellular distribution}

Currently, the mammalian UGT gene superfamily is known to consist of 117 members. In humans, four UGT families have been identified: UGT1, UGT2 (divided into subfamilies, 2A and 2B), UGT3 and UGT8. First two families, UGT1 and UGT2, use UDPGA to glucuronidate endo- and xenobiotics. This is not valid for the UGT8 and UGT3 family. The UGT8 enzymes has a biosynthetic role in the nervous system and use the UDP-galactose to galactosidate ceramides (which is an important step in the synthesis of glycosfingolipids and cerebrosides). The function of the UGT3 family was unclear for a long time. Recently UGT3A1 was identified as a UDP $\mathrm{N}$-acetylglucosaminyltransferase ${ }^{7}$.

The enzymes of each family share at least $40 \%$ homology in their DNA sequences and the enzymes of each subfamily share at least $60 \%$ homology in their DNA sequences $^{8}$. According to the nomenclature, Arabic numerals represent the family (e.g., UGT1). A letter designates the subfamily (e.g., UGT1A) and the second Arabic numeral denotes the individual gene (e.g., UGT1A1) (ref. ${ }^{9}$ ).

Recently, twenty-two human UGT proteins were identified: UGT1A1, 1A3, 1A4, 1A5, 1A6, 1A7, 1A8, 1A9, 1A10, 2A1, 2A2, 2A 3, 2B4, 2B7, 2B10, 2B11, 2B15, 2B17, 2B28, 3A1, 3A2 and 8A1 $1^{7,10-13}$. Many of these forms, but not all, are shown to have broad tissue distribution with liver as a major location. The UGT1A1, 1A3, 1A4, 1A6, 1A9, 2B7 and 2B15 enzymes are considered to be the most important human liver drug metabolising UGT forms. Extrahepatic glucuronidation has also been described. Several UGT forms are expressed mainly in the gastrointestinal tract e.g. UGT1A7, UGT1A8 and UGT1A10 ${ }^{14-16}$. Intestinal UGTs are presumed to be of particular importance in the first-pass metabolism of dietary supplements and drugs. They can also influence their oral bioavailability. Kidney ${ }^{17}$, brain and pancreas ${ }^{18}$, placenta $^{19}$ and nasal epithelium ${ }^{13}$ also exert glucuronidation activity.

In general, the UGTs are bound to the endoplasmic reticulum and the substrate binding sites are exposed to the lumen ${ }^{20}$.

\section{Substrates, inhibitors and inductors of UGTs}

Most UGTs have been shown to exhibit overlap in substrate specificities. To date, only a few substrate-selective forms of UGT have been identified. UGT1A1 is

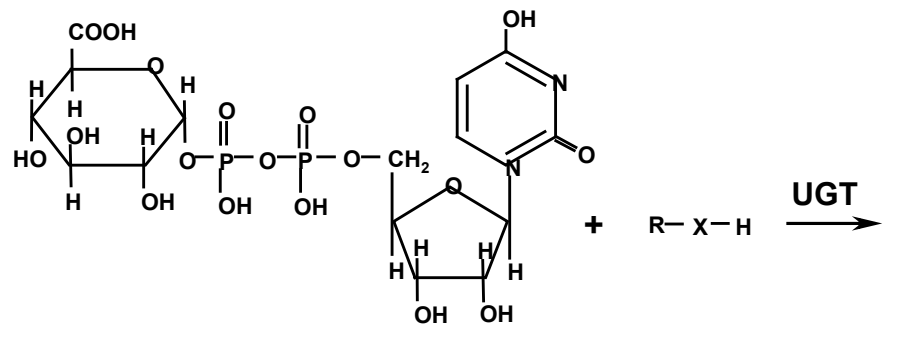

Uridine-5'-diphospho- $\alpha$-D-glucuronic acid

Nucleofile substrate

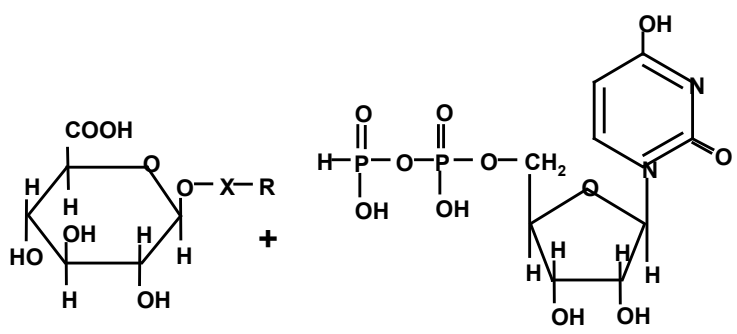

$\beta$-D-Glucuronide

Fig. 2. Conjugation of a nucleophile substrate with uridine-5'-diphospho- $\alpha$-D-glucuronic acid. 
the only isoform responsible for bilirubin glucuronidation $^{21}$. UGT1A1 exhibits moderate activity in the conjugation of simple phenols, anthraquinones/flavonones and $\mathrm{C}_{18}$ steroids and low activity in the conjugation of complex phenols and coumarins ${ }^{20}$. UGT2B7 is the major enzyme responsible for the glucuronidation of opioids $^{22}$. UGT1A3, UGT1A9, and UGT2A1 are the major enzymes of the conjugation of carboxylic acids, UGT1A4 and UGT1A3 catalyze the N-glucuronidation of amines. UGT1A6 preferentially conjugates complex phenols and primary amines ${ }^{10,20,23}$. The selectivity of UGT1A3 toward carboxylic acid-containing compounds (aliphatic or aromatic) has also been described ${ }^{24}$. Chen et al. ${ }^{25}$ confirmed the formation of glucuronides of flavonoids by UGT1A9 and 1A3. Lewinsky et al. ${ }^{26}$, found that 34 of 42 tested bioflavonoids were glucuronidated by UGT1A10.

Two selective inhibitors of UGT forms have been discovered. Hecogenin (steroidal saponin) is responsible for inhibition of UGT1A4, and flucoconazole inhibits UGT2B7 activity ${ }^{27,28}$. Bilirubin, the specific substrate of UGT1A1, has been shown to inhibit the enzymatic activity of UGT1A $4^{29}$.

Analgetics, nonsteroidal anti-inflammatory drugs (NSAD), antiviral drugs, anticonvulsants and anxiolytics/sedatives have been described as putative inhibitors of drug glucuronidation in humans.

Further, some drugs (analgetics, antivirals and anticonvulsants) may act as putative UDP-glucuronosyltransferase inducers in humans (e.g. rifampin increases codeine oral clearance and glucuronidation of debrisoquine) (ref. ${ }^{23,30}$ ).

\section{Genetic polymorphism in UGTS}

Studies of UGTs in humans have shown that several diseases are directly related to the pharmacogenetics of these enzymes. Genetic polymorphisms have been identified for the following UGT enzymes: UGT1A1, UGT1A3, UGT1A4, UGT1A6, UGT1A7, UGT1A8, UGT1A9, UGT1A10, UGT2A1, UGT2B4, UGT2B7, UGT2B10, UGT2B15, and UGT2B28 $8^{31-34}$.

Kadakol et al. ${ }^{35}$ compiled information on more than 50 mutations of UGT1A1 that cause Crigler-Najjar syndrome type I (including 9 novel mutations) or type II (including 3 novel mutations). These authors also presented a correlation of structure to function for UGT1A1.

The Crigler-Najjar syndrome was first described under the title 'congenital familial nonhemolytic jaundice with kernicterus', in 1952. Crigler-Najjar types I and II are autosomal recessive disorders ${ }^{36,37}$. Type I patients have complete absence of bilirubin UDP-glucuronosyltransferase (UGT1A1). Type II patients have a partial deficiency of this enzyme are less severely jaundiced and generally survive into adulthood without neurologic or intellectual impairment.

Gilbert syndrome is an autosomal dominant disorder caused by mutation in the UGT1 gene causing mild hyperbilirubinemia compared to the Crigler-Najjar syndrome. Gilbert syndrome is a benign, mild, unconjugated hyperbilirubinemia that is found in approximately $10 \%$ of the population $^{38}$.

\section{Interspecies differences in UGT enzymes}

In man and some other species, conjugation with glucuronic acid represents by far the most important metabolic pathway. A couple of studies have shown interspecies differences in the glucuronidation process. For example, differences in the formation and stereoselectivity of silybin glucuronides by liver microsomes of man, monkey, pig, dog and rat were described by Matal et al. ${ }^{39}$. Species differences in the glucuronidation of Beviramat, an anti-HIV drug candidate, have been demonstrated in human, rat, mouse, dog and marmoset liver microsomes ${ }^{24}$. Species differences between human, rats, dogs and monkeys in the N-glucuronidation of the muscle relaxant Afloqualone were described by Kaji and Kume ${ }^{40}$. Some studies have demonstrated that cats have remarkably low hepatic levels of UGT1A6. This means that this species exhibits deficient paracetamol ${ }^{41}$, acetaminophen ${ }^{42}$ and serotonin glucuronidation ${ }^{43}$.

\section{SULFOTRANSFERASES (SULTs; EC 2.8.2.1)}

Sulfotransferases are a supergene family of enzymes that catalyse the conjugation of 3'-phosphoadenosine 5'-phosphosulphate (PAPS) with an O-, N- or S- acceptor group of an appropriate molecule (Fig. 3). In general, $O$-sulfation represents the dominant cellular sulfonation reaction. Nevertheless, $N$-sulfation is a crucial reaction in the modification of carbohydrate chains in macromolecules such as heparin and heparan sulfate, common components of proteoglycan ${ }^{44}$. $\mathrm{N}$-Sulfoconjugation is also involved in the metabolism of xenobiotics such as quinolones and amino drugs ${ }^{45}$. The PAPS is a universal sulfate (or, correctly sulfonate) donor molecule required for all sulfonation reactions and shown that it can be synthesized by all tissues in mammals ${ }^{46}$.

Sulfonate conjugation was first described by Baumann in 1876. SULTs are probably the major detoxification enzyme system in the developing human fetus: no UGT transcripts were detected in fetal liver at 20 weeks of gestation $^{47}$. Human fetal liver cytosolic fractions have demonstrated significant sulfotransferase activity towards a large number of substrates (e.g. cortisol, dopamine, paracetamol, testosterone, pregnenolone, estrogen) (ref. $\left.{ }^{48}\right)$.

Sulfonation has a significant role in the biotransformation of a number of endogenous low-molecular compounds (e.g. steroids, catecholamines, serotonin, iodothyronines, eicosanoids, some tyrosine-containing peptides, retinol, 6-hydroxymelatonin, ascorbate and vitamin D) (ref. ${ }^{49}$ ). Moreover, it is an important pathway in the biotransformation of numerous xenobiotics such as drugs and chemicals ${ }^{50}$. On the other hand, a number of compounds (procarcinogens) are converted by sulfonation into highly reactive intermediates which can act as chemical carcinogens and mutagens by covalently binding to $\mathrm{DNA}^{51}$. 

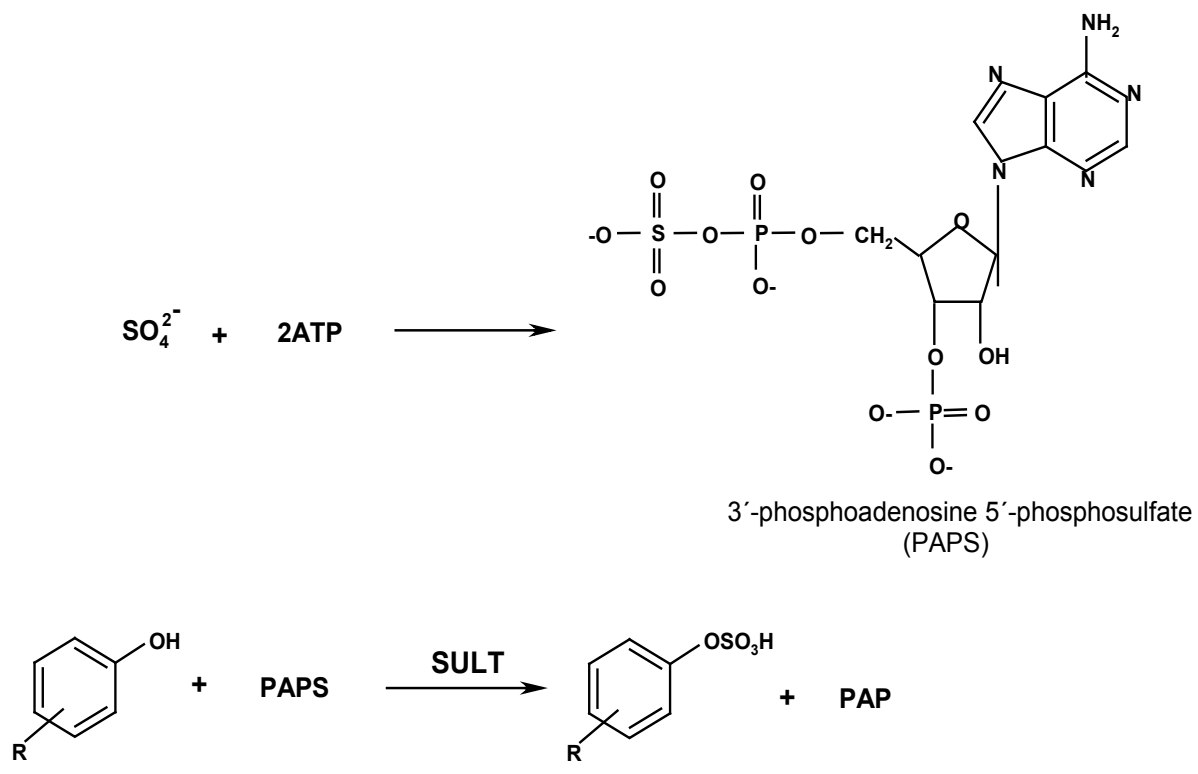

Fig. 3. General reaction catalyzed by SULT.

\section{SULTs: Forms, tissue and cellular distribution}

To date, four humans SULT families, SULT1, SULT2, SULT4 and SULT6, have been identified with at least 13 distinct members. The SULT1 family involves 9 members divided into 4 subfamilies (1A1, 1A2, 1A 3 and 1A4; $1 \mathrm{~B} 1 ; 1 \mathrm{C} 1,1 \mathrm{C} 2$ and $1 \mathrm{C} 3 ; 1 \mathrm{E} 1)$. The SULT2 family can be divided into two subfamilies, SULT2A (SULT2A1) and SULT2B. The SULT2B subfamily is comprised of two isoforms SULT2B1a and SULT2B1b. The SULT4A1 and SULT6B1 are the only members of the SULT4 and SULT6 family respectively ${ }^{52}$. The members of the same SULT gene family share at least $45 \%$ amino-acid sequence identity while members of subfamilies share at least $>60 \%$ identity in amino acid sequence ${ }^{53}$.

Two broad classes of sulfotransferases have been identified: namely the cytosolic and membrane-bound ones. Membrane-bound SULTs are localized in the Golgi apparatus and are responsible for the sulfonation of peptides, proteins, lipids and glycosamoniglycans. Cytosolic SULTs catalyze sulfonation of xenobiotics and small endobiotic molecules such as steroids, bile acids and neurotransmitters $^{50}$

SULTs exhibit wide tissue distribution. The members of SULT1A subfamily have been identified in liver, brain, breast, intestine, jejunum, lung, adrenal gland, endometrium, placenta, kidney and blood platelets. SULT1A1 exhibits the highest level of expression of all SULT1 enzymes in the liver. In contrast, SULT1A3 is expressed in most tissues with the exception of adult liver and SULT1B1 in liver, small intestine, colon and leukocytes. Expression of the SULT1C subfamily is found predominantly in the human fetus (fetal kidney, lung, heart and gastrointestinal tract). SULT1E1 is expressed in the human liver and jejunum. Fetal liver, lung and kidney also showed high level of SULT1E1. SULT2A1 shows the highest level of expression in liver, adrenal, duodenum and fetal adrenal gland. Subfamily SULT2B is localized in human prostate, placenta, adrenal gland, ovary, lung, kidney and colon ${ }^{49}$, 50, 52. Human SULT4A1 has been identified in brain ${ }^{54,55}$ and SULT6B1 in testis and kidney ${ }^{56}$.

\section{Substrates, inhibitors and inductors of SULTS}

SULT enzymes have different substrate preferences although there is evidence of substrate overlap at the levels of subfamilies and families.

SULT1A1 is a xenobiotic-conjugating enzyme with a broad substrate range. It has also been termed phenol sulfotransferase (P-PST) and thermostable phenol sulfotransferase (TS PST1). This form is responsible for the sulfoconjugation of phenolic compounds such as monocyclic phenols, naphtols, benzylic alkohols, aromatic amines, hydroxylamines, dopamine and iodothyronines ${ }^{49}$. 4-nitrophenol has been widely used to selectively detect SULT1A1 activity ${ }^{57}$.

SULT1A2 (TS PST2) appears to be an efficient enzyme for sulfoconjugation of several aromatic hydroxylamines $^{58}$, and this reaction may be taken as an example of a toxification reaction, contrary to detoxication reactions occuring in the majority of cases. Charged species (the sulfoconjugates of hydroxylamines) formed in this reaction are chemically reactive and mutagenic. The physiological role of SULT1A2 has not been identified yet. SULT1A2 can sulfoconjugate substrates such as 2-naphtol or 4-nitrophenol ${ }^{49}$. Although, SULT1A2 shares $>93 \%$ aminoacid identity with SULT1A1 and SULT1A3, this enzyme exhibits no activity toward dopamine as a substrate $^{50}$.

SULT1A3 was previously known as thermolabile phenol SULT (TL PST) and monoamine sulfotransferase (M-PST). It displays high affinity for monocyclic phenols. SULT1A3 has a specific role in the sulfonation of catecholamines and as such is responsible for the regula- 
tion of the rapidly fluctuating levels of neurotransmitters. Dopamine is often used as a selective substrate for the detection of SULT1A3 activity ${ }^{59}$. Other substrates include norepinephrine, catechols, monocyclic phenols and aromatic molecules ${ }^{50}$.

The substrate specifity of SULT1B1 is restricted to thyroid hormones ${ }^{60}$ and small phenolic compounds such as 1-naphtol and 4-nitrophenol ${ }^{61}$.

SULT1C1 conjugates some iodothyronines ${ }^{62}$ but a good substrate for this enzyme has not been identified. SULT1C2 showed activity for substrates as 4-nitrophenol and $N$-hydroxy-2-acetylaminofluoren ${ }^{63}$.

SULT1E1 was also called estrogen sulfotransferase (EST). This enzyme has a greater affinity for estrogen sulfation ${ }^{64}$ than any other SULTs which conjugate estrogen. SULT1E1 may be important in both the metabolism of estrogens and in the regulation of their activities. This enzyme also shows activity towards iodothyronines, pregnenolon, 1-naphtol, naringenin, genistein and 4-hydroxytamoxifen ${ }^{50}$.

SULT2A1 was termed dehydroepiandrosterone-sulfotransferase (DHEA ST). This form is responsible for the sulfoconjugation of hydroxysteroids such as DHEA, androgens, bile acids and oestrone ${ }^{65}$.

SULT2A and SULT2B subfamilies metabolize similar substrates but members of the SULT2B subfamily are predominantly cholesterol sulfotransferases ${ }^{66}$.

To date no substrates have been identified for SULT4A1 or SULT6B1.

SULT activity may be inhibited in humans exposed to certain therapeutic drugs, dietary or environmental chemicals ${ }^{67}$. The inhibitory effects of various compounds have been examined mainly for the SULT1A subfamily. Vietri et al. ${ }^{68}$ described curcumin as a potent inhibitor of SULT1A1 in human liver. De Santi et al. ${ }^{69}$ showed inhibition of SULT1A1 by quercetin in human adult and fetal liver. The inhibitory effects of various beverages and catechins in tea were investigated by Nishimuta et al. ${ }^{70}$. Their results showed inhibition of recombinant SULT1A1 and 1A3 by grapefruit juice, orange juice, green tea, black tea and oolong tea. An inhibitory effect of some non-steroidal anti-inflammatory agents on SULT1A1 and SULT1E1 activity was demonstrated by King et al. ${ }^{71}$. Nimesulide, meclofenamate, piroxicam were selective inhibitors of SULT1A1 while sulindac and ibuprofen were more selective for SULT1E1 inhibition.

Maiti et al. ${ }^{72}$ found that retinoic acid can increase sulfotransferase expression and activity in cultured human cells. They reported retinoic acid induction of human SULT1A1, 2A1 and 1E1 in hepatic carcinoma cells (HepG2) and in intestinal carcinoma cells (Caco-2).

Methotrexate induced human SULTs in HepG2 and Caco-2 cells ${ }^{73}$. Chen el al. ${ }^{73}$ showed that protein and mRNA expression of human SULT1A1, 1A3, 2A1, 1E1 were induced in HepG2 cells; SULT1A3 and 2A1 were induced in Caco- 2 cells. Sulfotransferase expression in HepG2 and Caco- 2 cell lines was also investigated by Chen et al. ${ }^{74}$. Their data suggested that genistein, a natural isoflavone found in soybean products induced SULT1A1 and SULT2A1 gene and protein expression in these cells.

\section{Genetic polymorphism in SULTS}

Genetic polymorphism is known for the major form in adult human liver SULT1A1. Common single nucleotide polymorphism results in an $\mathrm{Arg}_{213} \rightarrow$ His amino acid substitution resulting in variation of activity and thermal stability. This mutation was found with a frequency of 25.4 - 36.5\% in Caucasians ${ }^{49}$. Individuals who are homozygous for $\mathrm{His}_{213} / \mathrm{His}_{213}$ have significantly reduced platelet sulfotransferase activity.

Genetic polymorphism is also known for SULT1A2, 1A3, 1C2, 2A1, 2A3, 2B1 ${ }^{52}$. Several studies have demonstrated that SULT1A1 polymorphism may play a role in the development of cancers such as lung cancer ${ }^{75}$, urothelial carcinoma ${ }^{76}$ and meningiomal brain tumors ${ }^{77}$.

\section{Interspecies differences in SULTS}

There is a dearth of information about interspecies differences in SULT enzymes. In some species, SULT forms were isolated that have no equivalent human form. Tsoi et al. ${ }^{78}$ identified a canine SULT1D1. No equivalent human form of this enzyme has been identified. The SULT3 family was found in rabbit ${ }^{79}$ and SULT5AI was confirmed in mice ${ }^{80}$. On the other hand, SULT1A2 has not been identified in any other species than human ${ }^{50}$.

Moreover, Wang et al. ${ }^{81}$ described a different dopamine metabolism in man and rat showing that dopamine was entirely sulfoconjugated in human but glucuronidated in rat.

In rodents, SULTs exhibit dramatic sexual dimorphism in SULT expression. The SULT enzyme RNAs from both male and female rats were found in highest concentration in liver. SULT1A1, 1C1 and 1E2 are designated as maledominant sulfotransferases. On the other hand, members of the SULT2 family are predominant for females ${ }^{82}$.

\section{N-ACETYLTRANSFERASES (NATs; EC 2.3.1.5)}

Liver arylamine $\mathrm{N}$-acetyltransferases (acetyl CoAdependent $\mathrm{N}$-acetyltransferases, NATs) of adults are involved in the biotransformation of aromatic amines and hydrazines by transfer of the acetyl group from acetylcoenzyme A to the free amino group of parent compound (Fig. 4). NATs catalyze the activation of aromatic and heterocyclic amines (4-aminobiphenyls) via $O$-acetylation while $N$-acetylation of the parent amines is considered a detoxification step ${ }^{83}$. Arylamine $N$-acetyltransferases are present in eukaryotic organisms, including humans, and their existence has been also confirmed in the prokaryote Salmonella typhimurium ${ }^{84,85}$.

The role of NAT in endogenous metabolism is unclear.

\section{NAT forms; tissue and cellular distribution}

NATs are cytosolic enzymes found in many tissues of various species. In humans, two forms are known, NAT1 and NAT2. Two functional human gene loci, NATland $N A T 2$ were identified and characterized for humans and mapped to the short arm of human chromosome 8 . The nucleotide sequences of these two genes show $85 \%$ homology and code two enzymes of different substrate spe- 


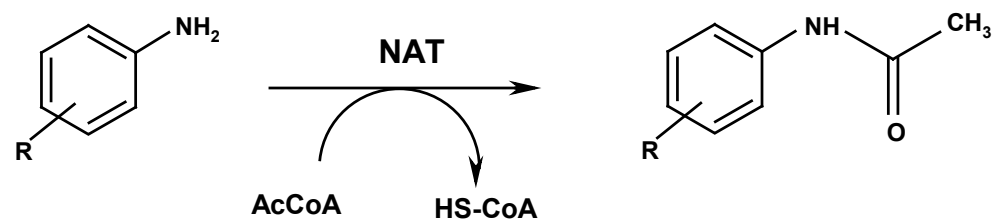

Fig. 4. Acetylation of arylamines by NAT.

cificity. In 2000, 25 human NAT1 and 27 human NAT2 alleles were identified ${ }^{83}$. Despite this high level of homology, NATs have distinct tissue distribution and substrate specificity. NAT1 has a ubiquitous tissue distribution and its expression has been demonstrated to be realated to cancers. NAT2 activity has been described in liver, colon and intestinal epithelium.

\section{Substrates, inhibitors and inductors of NATs}

Human NAT1 and human NAT2 have different substrate specificities. Typical specific substrates for human NAT1 are: $p$-aminobenzoic acid (PABA), $p$-aminosalicylic acid and $p$-aminobenzylglutamate ${ }^{86}$. Sulfamethazine is used as a NAT2-selective substrate ${ }^{87}$. Human NAT2 provides a major route for detoxification of drugs such as isoniazid (antituberculotic drug), hydralazine (antihypertensive drug) and sulphonamides (antibacterial drugs) $\left(\right.$ ref. $\left.{ }^{86}\right)$.

The inhibitory effect of polyphenolic compounds on human NATs has been described. Caffeic acid, esculetin, quercetin, kaemferol and genistein inhibited NAT1 whereas scopuletin and coumarin inhibited NAT $2^{88}$. Chen et al. ${ }^{89}$ and Lin et al. ${ }^{90}$ described the effect of diallyl sulfide (DAS) and diallyl disulfide (DADS), major components of garlic, on NAT activity in human colon tumor cells and human promyelocytic leukemia cells. These studies demonstrated that DAS and DADS markedly inhibited NAT activity in these cells and would thus assist the organism in defense against cancer.

To date, little is known about the induction of NATs. In 2007, Butcher et al. ${ }^{91}$ investigated the effects of androgens on the expression of NAT1 in human prostate cancer cells. The results showed that human NAT1 is induced by androgens.

\section{Genetic polymorphism in NATs}

Arylamine N-acetyltransferases, NAT1 and NAT2, are the polymorphic enzymes responsible for the 'acetylator phenothype'. Individual differences in the NATs metabolic capacity are caused by allelic variations of the NATs gene which are determined by pattern single nucleotide polymorphisms resulting in slow, intermediate or rapid acetylator phenotypes. Rapid and slow acetylations have been demonstrated to be a predisposing factor for the sensitivity of individuals to toxicity through exposure to a large number of arylamines. The frequency of the specific mutations within the NAT loci depends on racial and ethnic origin. Phenotyping analyses have revealed an association between NAT2 slow acetylation genotype and the risk of developing of several forms of cancer such as lung, colon, liver or bladder cancer ${ }^{92}$. Lammer et al. ${ }^{93}$ found evidence suggesting an interaction between NAT1 polymorphism, lack of maternal multivitamin use and association with birth defects (cleft lip).

\section{Interspecies differences in NATS}

NATs are cytosolic enzymes found in many tissues of a number of species. Animal models, such as mice, rats, hamsters or rabbits, have been used to study the relationship between the human NATs polymorphism and toxicity. It has been shown that acetylation of heterocyclic amines is species- and substrate-dependent. The substrate specificity in some species differs from the human one. Substrate $p$-aminobenzoic acid (PABA) is a selective substrate for human NAT1. In rodents it is a substrate for NAT2. There is an $82 \%$ identity at the amino acid level between mouse NAT2 and human NAT $1^{94}$. In 2006, Walraven et al. ${ }^{95}$ identified and characterised a third rat NAT gene (NAT3).

NATs have been found to have high activity in rats. Humans exhibit an intermediate activity of NATs and dogs totally lack this enzyme family ${ }^{96}$.

In the rabbit, more than $80 \%$ of all acetylating capacity is localized in the liver and gut. Polymorphic genes leading to slow and rapid acetylating phenotypes have also been found in rabbits. Hence, rabbit NAT represents a good animal model for the human acetylation polymorphism ${ }^{97}$.

\section{GLUTATHIONE S-TRANSFERASES (GSTs; 2.5.1.18)}

Glutathione S-transferases, one of the major phase II detoxification enzymes are involved in the metabolism of xenobiotics and play an important role in cellular protection against oxidative stress.

The GSTs are a family of enzymes that catalyze the formation of thioether conjugates between the endogenous tripeptide glutathione and xenobiotic compounds (Fig. 5). GSTs can catalyze a large number of reactions including nucleophilic aromatic substitutions, Michael additions, isomerations and reduction of hydroperoxides, conjugation of many hydrophobic and electrophilic compounds with reduced glutathione. GSTs play a major role in the detoxication of epoxides derived from polycyclic aromatic hydrocarbons (PAHs) and alpha-beta unsaturated ketones. Moreover, a number of endogenous compounds such as prostaglandins and steroids are metabolized via glutathione conjugation ${ }^{98}$.

The major biological function of glutathione transferases appears to be defense against reactive and toxic 
<smiles>[R]CC(NC(=O)CCC(N)C(=O)O)C(=O)NCC(=O)O</smiles>

Glutathione

Glutathione-S-conjugate

Fig. 5. Formation of glutathione conjugate.

electrophiles such as reactive oxygen species (superoxide radical and hydrogen peroxide) that arise through normal metabolic processes. Many of these are formed by cellular oxidative reactions catalyzed by cytochrome P450 and other oxidases ${ }^{99}$.

\section{GST forms; tissue and cellular distribution}

Two distinct superfamilies of GSTs have been described. One comprises soluble dimeric enzymes that are involved in biotransformation of toxic xenobiotics and endobiotics. The soluble GST superfamily is subdivided into eight separate classes designated Alpha, Kappa, Mu, $\mathrm{Pi}$, Sigma, Theta, Zeta and Omega. Soluble GSTs have been described mainly in cytoplasm but they are also presented in nucleus, mitochondria ${ }^{100}$ and peroxisomes ${ }^{101}$. A number of GST classes were identified first in nonmammalian species and later recognized in mammals too. Human GST enzymes belong to classes Alpha (A1-A4), $\mathrm{Mu}$ (M1-M5), Pi (P1), Kappa (K1) and Theta (T1, T2) with their subunit composition or isoenzyme type designated by Arabic numerals. GSTs share more than 60\% identity within a class but less than $30 \%$ identity with separate classes.

The other superamily of GSTs designated as MAPEG (membrane-associated proteins in eicosanoid and glutathione metabolism), probably with trimeric structure, is involved in arachidonic acid metabolism ${ }^{99,102}$. Members of both GST families exhibit selenium-independent glutathione peroxidase activity.

Soluble GSTs and MAPEG are widely distributed throughout the body and found in liver, kidney, brain, pancreas, testis, heart, lung, small intestine, sceletal musles, prostate and spleen ${ }^{103}$.

\section{GSTs substrates, inhibitors and inductors}

Substrates for GSTs are all compounds able to react with the thiol moiety of glutathione. These are electrophilic compounds such as epoxides, $\alpha, \beta$-unsaturated ketones, quinones, sulfoxides, esters, peroxides and ozonides. The Alpha (A), Mu (M) and Pi (P) GST detoxify commonly incident harmful $\alpha, \beta$-unsaturated carbonyls (e.g. acrolein, 4-hydroxynonenal, adenine, thymine propenals) (ref. ${ }^{103}$ ). A number of specific substrates of GSTs have been described. Ethacrynic acid has been shown to be a very specific substrate for GST-P1 and trans-stilbene oxide is a diagnostic substrate for GST-M1. Relatively small molecules e.g. methylene chloride, ethylene dibromide or isoprene derivates have been shown to be conjugated by GST-T $1^{98}$. The 1-chloro-2,4-dinitrobenzene
(CDNB) has been described as a 'universal' GST substrate. However, theta class enzymes lack activity with this substrate ${ }^{99}$.

A large number of inhibitors of GST are known, e.g. synthetic and naturally-occurring phenols, quinones or derivatives of vitamin C. Kulkarni et al. ${ }^{104}$ described alltrans retinoic acid as an inhibitor of human placental and liver glutathione transferases in the micromolar range. GSTs have been found to be inhibited by glutathione derivatives or substrate analogs. Ploemen et al. ${ }^{105}$ describe inhibition of human GSTs by dopamine, $\alpha$-methyldopa and 5-S-glutathionyldopamine.

Extracts of Ginkgo biloba have been found to induce GST-P1 and elevated cellular GST activity in human cell lines ${ }^{106}$. Moreover, Williamson et al ${ }^{107}$ demonstrated which foods were inducers of the GST activity in humans. Their results showed that extracts from cruciferous vegetables (e.g. broccoli, Brussels sprouts, cabbage) as well as grapefruit extract act as inducers of human GSTs.

\section{Genetic polymorphism in GSTs}

Several types of allelic variations have been identified in the class Alpha, Mu, Pi, Theta GST gene families. Individuals lacking GST-M1, GST-T1 and GST-P1 genes have a higher incidence of bladder, breast, colorectal, head/neck and lung cancer. Loss of these genes have also been found to increase susceptibility to asthma and allergies, atherosclerosis and rheumatoid arthritis ${ }^{98,108 .}$ Little is known about polymorphism in MAPEG genes. Iida et al. ${ }^{109}$ described single-nucleotide polymorphism of MGST1 (a member of MAPEG) in healthy Japanese volunteers.

\section{Interspecies differences in GSTS}

Examination of hepatic cytosolic fractions prepared from mice, rats, Syrian Golden hamsters and humans show that murine liver possesses a significantly greater capacity to conjugate dichlormethane with GSH than livers from other species ${ }^{110}$. Sherratt et al. ${ }^{111}$ confimed that mouse GST-T1 had a higher specific activity than the human transferase toward dichlormethane and 1,2-epoxy3-(4'-nitrophenoxy) propane (1.8- and 16-fold higher, respectively). On the other hand, human GST-T1 had a 4.8-fold higher capacity than mouse isoenzyme to catalyze the reduction of cumene hydroperoxide.

Glutathione S-transferase activity toward 1-chloro-2,4dinitrobenzene, the 'universal' GST substrate, was investigated by Igarashi et al. ${ }^{112}$. These authors used GSTs of the hepatic cytosol of rats, mice, guinea pigs, rabbits and 
hamster. They showed that activity towards 1,2-dichloro4-nitrobenzene was the highest in hamster, followed by rabbits, guinea pigs, mice and rats.

\section{THIOPURINE S-METHYLTRANSFERASE (TPMT; EC 2.1.1.67)}

Thiopurine $S$-methyltransferase is an $S$-adenosylL-methionine dependent enzyme that catalyzes $S$-methylation of aromatic heterocyclic sulfhydryl compounds including anticancer and immunosuppressive thiopurines such as 6-mercaptopurine (6-MP), 6-thioguanine (6-TG) and azathioprine (Fig. 6). These drugs are used to treat acute lymphoblastic leukemia, autoimmune disorders, inflammatory bowel disease and organ transplant recipients ${ }^{113}$. Thiopurines 6-MP, 6-TG and azathioprine are prodrugs which need to be activated by the hypoxanthine phosphoribosyltransferase (Fig. 6); metabolic conversion by TPMT leads to the formation of inactive methylated metabolites ${ }^{114}$. Impaired activity of TPMT causes an accumulation of thiopurine nucleotides and manifestation of cytotoxicity leading to the failure of haemopoiesis in most cases.

\section{Tissue and cellular distribution of TPMT}

TPMT is a cytosolic enzyme with the highest levels in liver and kidney and relatively low levels in brain and lungs. Levels of TPMT activity in the red blood

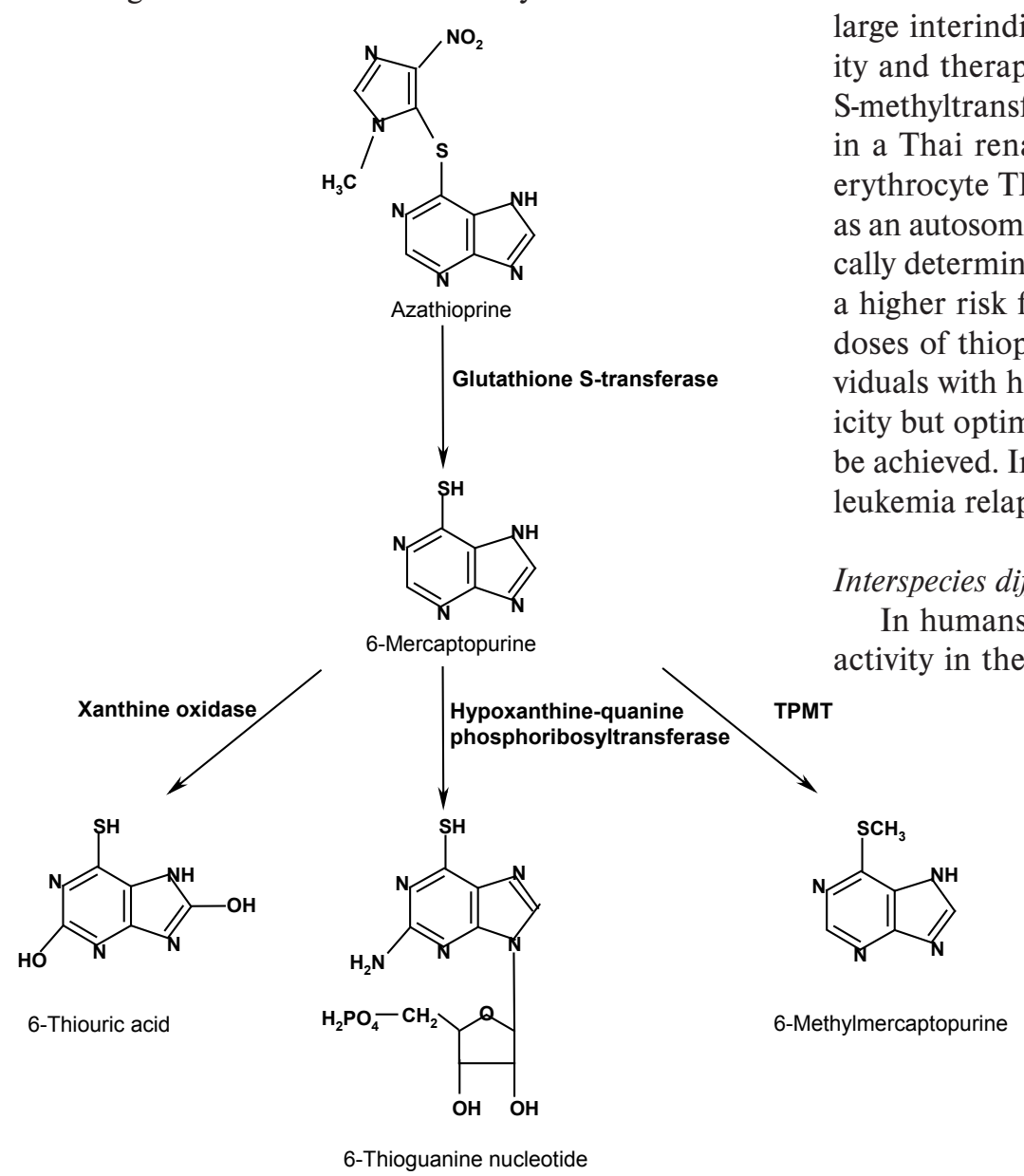

cells (RBC) correlate highly with levels of the enzyme activity in other human tissues (liver, kidney) and cells (lymphocyte) (ref. ${ }^{115,116}$ ). Klemetsdal et al. ${ }^{117}$ found that RBC TPMT activity was $8.3 \%$ higher in healthy males than healthy females. Erythrocyte activity in newborns is higher (by about $50 \%$ grater) than in healthy adults ${ }^{118}$.

\section{TPMT substrates and inhibitors}

TPMT is an important enzyme in the metabolism of thiopurine substances. No endogenous substrate is known for this enzyme and its biological role remains unidentified. Recently, Oselin and Anier ${ }^{114}$ have investigated the inhibitory potential of 15 non-steroidal anti-inflammatory drugs on human TPMT activity in vitro. Naproxen, mefenamic and tolfenamic acid inhibited TPMT activity in a noncompetitive manner. These autors described weak inhibition of TPMT by ketoprofen and ibuprofen. Olsalazine, 5-aminosalicylic acid and sulphasalazine have also been described as noncompetitive inhibitors of TPMT as well ${ }^{119}$.

\section{Genetic polymorphism in TPMT}

The level of TPMT activity in human tissues is regulated by genetic polymorphism. Allele frequencies for genetic polymorphism are such that $\sim 1$ in 300 Caucasians is homozygous for a defective allele or alleles for the trait of very low activity, $\sim 11 \%$ of people are heterozygous and have intermediate activity ${ }^{120}$. In 2008, 23 alleles of TPMT were identified and this may be associated with large interindividual variations in thiopurine drug toxicity and therapeutic efficacy ${ }^{121}$. Novel human thiopurine S-methyltransferase (TPMT) variant allele was identified a Thai renal transplantation recipient with reduced a higher risk for side-effects when treated with standard doses of thiopurines. On the other hand, wild-type indibe achieved. In this instance, there is an increased risk of terspecies differences in TPMT

In humans and the other species, the level of TPMT

Fig. 6. Thiopurine metabolism. 
activity in peripheral red blood isolates. White et al. ${ }^{124}$ demonstrated significant differences in red blood cell TPMT activity values of three species (dog, cat, horse). Values from canine samples were significantly higher than those from cats or horses. These relatively low levels of activity may help to explain the sensitivity of cats to thiopurine therapy.

A difference in TPMT activity between human and pig has also been described. The levels of TPMT activity in human have been found to be twise as high as the TPMT activity in pig samples ${ }^{125}$.

\section{CATECHOL O-METHYL TRANSFERASE (COMT; EC 2.1.1.6)}

Catechol O-methyltransferase is responsible for transfer of a methyl group from S-adenosylmethionine to catecholamines. This O-methylation results in one of the major degradative pathways of the catecholamine transmitters (Fig. 7). COMT is an enzyme that plays a key role in the modulation of catechol-dependent functions such as cognition, cardiovascular function and pain processing.

COMT substrates include not only neurotransmitters such as norepinephrine, epinephrine and dopamine but also drugs having a catechol structure used in the treatment of hypertension, asthma and Parkinson's disease ${ }^{126}$. COMT was first discribed by Axelrod in 1957.

\section{COMT forms; tissue and cellular distribution}

COMT is an intracellular enzyme located in the postsynaptic neuron. COMT is presented in mammalian cells in two forms: in a cytoplasmic soluble form (S-COMT) and a membrane-bound form (MB-COMT) located in the cytosolic side of the rough endoplasmic reticulum ${ }^{127}$.

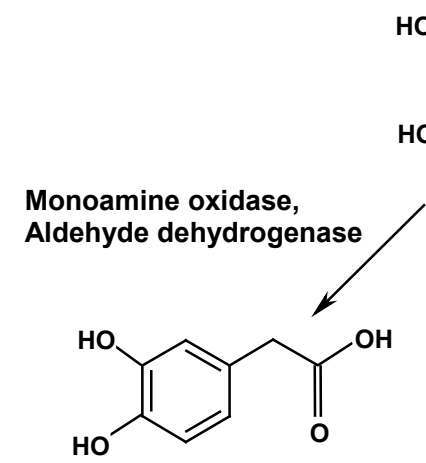

3,4-dihydroxyphenyl-acetic acid<smiles>NCCc1ccc(O)c(O)c1</smiles>
Dopamine

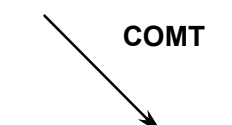

Primary structures of the two COMT forms are otherwise identical but differences between S-COMT and MBCOMT reside within the N-termini. The MB-COMT has an N-termini extension of about 50 amino acids. S-COMT is expressed at higher levels in most tissues than MBCOMT. The highest COMT activities have been found in liver, kidney, intestine, and brain ${ }^{128}$. S-COMT is predominatly expressed in peripheral tissues, while MB-COMT is mostly expressed in the brain. In the blood, COMT is found mainly in erythrocytes; in leukocytes its activity is low.

\section{COMT substrates and inhibitors}

Catechol-O-methyl transferase is involved in the inactivation of catecholamine transmitters such as norepinephrine, epinephrine and dopamine and also catecholestrogens and catechol drugs.

Several COMT inhibitors have been described such as entcapone, and tolcapone. COMT inhibitors have also been found in green tea e.g. flavonoid quercetin ${ }^{129}$. COMT inhibitors, entacapone and tolcapone, protect L-dopa from the action of COMT and thus prolong the action of this compound. Hence, they are a widely-used adjunct drugs in L-dopa therapy. When COMT inhibitors are given to patients together with an inhibitor of dopa decarboxylase (carbidopa or benserazide), L-dopa is optimally protected from degradation. This "triple therapy" is used in the treatment of Parkinson's disease ${ }^{130}$.

\section{Genetic polymorphism in COMT}

A functional single nucleotide polymorphism of the gene for catechol-O-methyl transferase (VAL 108/158 MET) has been identified. The level of COMT enzyme activity (low, intermediate and high levels) is genetically polymorphic in human red blood cells and liver. This polymorphism is due to a G-to-A transition at codon 158 (for MB-COMT) or codon 108 (for S-COMT) of the COMT gene and results in the substitution of the amino acid valine for methionine causing a decrease in the activity level of the COMT enzyme 3 to 4 fold $^{131}$.

Functional polymorphism in the COMT gene (VAL $108 / 158$ MET) has been examined in relationship to a number of neurological disorders involving the noradren-

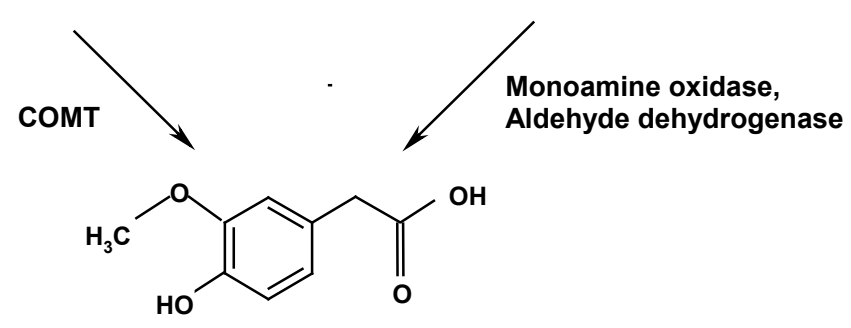

Homovanilic acid

Fig. 7. Degradative pathway of dopamine. 
ergic or dopaminergic systems, such as schizophrenia ${ }^{132-134}$ and Parkinson's disease ${ }^{135,136}$.

It has been suggested that a common functional genetic polymorphism in the COMT gene may contribute to the etiology of alcoholism. The results of Tiihonen et al. ${ }^{137}$; Kauhanen et al. ${ }^{138}$ indicate that COMT polymorphism contributes significantly to the development of late-onset ( $\geq 25$ years) alcoholism. An association of COMT low activity with early-onset ( $<25$ years) alcoholism has been demonstrated as well ${ }^{139}$.

\section{Interspecies differences in COMT}

COMT influences dopamine concentration in the prefrontal cortex (PFC). Dopaminergic neurotransmission in the PFC contributes to individual cognitive differences in animals and humans.

The human COMT amino acid sequence was compared with those of the chimpanzee, gorilla, orangutan, bonobo, dog, cat, rat, mouse and pig. Alanine at codon position 52/102 was found in all these species except the pig. Pig had the variant human amino acid (threonine) at this position. Methionine, the amino acid encoded by the variant human allele at codon 108/158 was not confirmed among tested species at that position ${ }^{126}$.

The amino acid at the Val/Met locus is important for COMT activity. It has been hypothesised that COMT activity has decreased over the course of evolution ${ }^{140}$.

\section{CONCLUSION}

Products of Phase II reactions are conjugates that are rapidly excreted in bile and urine. They are generated by the transfer of a specific moiety from coenzyme to endogenous or exogenous substrates. The enzymes are generally known as transferases. Phase II reactions involve glucuronidation, sulfation, methylation, acetylation, glutathione and amino acid conjugation. UDP-glucuronosyltransferases, sulfotransferases, $\mathrm{N}$-acetyltransferases, glutathione S-transferases and various methyltransferases (thiopurine S-methyl transferase and catechol O-methyl transferase) are considered the major phase II enzymes. Phase II drug metabolizing enzymes play an important role in the biotransformation of endogenous compounds and xenobiotics to more easily excretable forms as well as in the metabolic inactivation of pharmacologically active compounds. Although phase II reactions are generally detoxifying, the conjugates formed may also mediate adverse effects. A number of compounds (procarcinogens) are converted by Phase II enzymes into highly reactive intermediates which can act as chemical carcinogens and mutagens by covalent binding to DNA. The reduced capacity of the Phase II enzymes to metabolise drugs may lead to the appearance of toxic effects of clinically used drugs. Moreover, several studies have provided evidence that gene polymorphism or lack of the genes for these enzymes may play a role in the development of several forms of cancer. Phase II biotransformation is hence an important aspect of human toxicology.

\section{ACKNOWLEDGMENT}

This work was supported by the grant from the Czech Ministry of Education (Grant No. MSM 6198959216), the GACR project 303/09/H048 and grant LF_2010_022.

\section{REFERENCES}

1. Anzenbacher P, Anzenbacherova E. Cytochromes P450 and metabolism xenobiotics. Cell Mol Life Sci 2001; 58(5-6):737-747.

2. Glatt H. Sulfotransferases in the bioactivation of xenobiotics. Chem Biol Interact 2000; 129(1-2):141-170.

3. Wells PG, Mackenzie PI, Chowdhury JR, Guillemette C, Gregory PA, Ishii Y, Hansen AJ, Kessler FK, Kim PM, Chowdhury NR, Ritter JK. Glucuronidation and the UDP-glucuronosyltransferases in health and disease. Drug Metab Dispos 2004; 32(3):281-290.

4. Kiang TKL, Ensom MHH, Chang TKH. UDP-glucuronosyltransferases and clinical drug-drug interactions. Pharmacol Ther 2005; 106(1):97-132.

5. Cashman JR, Perotti BYT, Berkman CE, Lin J. Pharmacokinetics and molecular detoxication. Environ Health Perspect 1996; 104:23-40.

6. Fisher MB, Paine MF, Strelevitz T, Wrighton SA. The role of hepatic and extrahepatic UDP-glucuronosyltransferases in human drug metabolism. Drug Metabol Rev 2001; 33(3-4):273-297.

7. Mackenzie PI, Rogers A, Treloar J, Jorgensen BR, Miners JO, Meech R. Identification of UDP glycosyltransferase $3 \mathrm{~A} 1$ as a UDP N-acetylglucosaminyltransferase. J Biol Chem 2008; 283(52):36205-36210.

8. Burchell B, Brierley CH, Rance D. Specificity of human UDPglucuronosyltransferases and xenobiotic glucuronidation. Life Sci 1995; 57(20):1819-1831.

9. Mackenzie PI, Bock KW, Burchell B, Guillemette C, Ikushiro S, Iyanagi T, Miners JO, Owens IS, Nebert DW. Nomenclature update for the mammalian UDP glycosyltransferase (UGT) gene superfamily. Pharmacogenet Genomics 2005; 15(10):677-685.

10. Miners JO, Knights KM, Houston JB, Mackenzie PI. In vitro-in vivo correlation for drugs and other compounds eliminated by glucuronidation in humans: pitfalls and promises. Biochem Pharm 2006; 71(11):1531-1539.

11. Court MH, Hazarika S, Krishnaswamy S, Finel M, Williams JA. Novel polymorphic human UDP-glucuronosyltransferase (UGT) 2A3: Cloning, functional characterization of enzyme variants, comparative tissue expression, and gene induction. Mol Pharmacol 2008; 74(3):744-754.

12. Patten CJ. New technologies for assessing UDP-glucuronosyltransferase (UGT) metabolism in drug discovery and development. Drug Discov Today Tech 2006; 3(1):73-78.

13. Sneitz N, Court MH, Zhang X, Laajanen K, Yee KK, Dalton P, Ding X, Finel M. Human UDP-glucuronosyltransferase UGT2A2: cDNA construction, expression, and functional characterization in comparison with UGT2A1 and UGT2A3. Pharmacogenet Genomics 2009; [Epub ahead of print].

14. Gregory PA, Lewinsky RH, Gardner-Stephen DA, Mackenzie PI. Regulation of UDP glucuronosyltransferases in the gastrointestinal tract. Toxicol Appl Pharmacol 2004; 199: 354-363.

15. Tukey RH, Strassburg CP. Genetic multiplicity of the human UDPglucuronosyltransferases and regulation in the gastrointestinal tract. Mol Pharmacol 2001; 59: 405-414.

16. Cheng Z, Radominska-Pandya A, and Tephly TR. Studies on the substrate specificity of human intestinal UDP-glucuronosyltransferases 1A8 and 1A10. Drug Metab Dispos 1999; 27: 1165-1170.

17. Sutherland L, Ebner T, Burchell B. The expression of UDPglucuronosyltransferases of the UGT1 family in human liver and kidney and in response to drugs. Biochem Pharmacol 1993; 45(2):295-301.

18. King CD, Rios GR, Assouline JA, Tephly TR. Expression of UDPglucuronosyltransferases (UGTs) 2B7 and 1A6 in the human brain 
and identification of 5-hydroxytryptamine as a substrate. Arch Biochem Biophys 1999; 365(1):156-62.

19. Collier AC, Ganley NA, Tingle MD, Blumenstein M, Marvin KW, Paxton JW, Mitchell MD, Keelan JA. UDP-glucuronosyltransferase activity, expression and cellular localization in human placenta at term. Biochem Pharmacol 2002; 63(3):409-419.

20. Tukey RH and Strassburg CP. Human UDP-glucuronosyltransferases: metabolism, expression, and disease. Annu Rev Pharmacol Toxicol 2000; 40: 581-616.

21. Wang X, Chowdhury JR, Chowdhury NR. Bilirubin metabolism: Applied physiology. Curr Paediatr 2006; 16(1):70-74.

22. Coffman BL, King CD, Rios GR, Tephly TR. The glucuronidation of opioids, other xenobiotics, and androgens by human UGT2B7Y(268) and UGT2B7H(268). Drug Metab Dispos 1998; 26(1):73-77.

23. King CD, Rios GR, Green MD, Tephly TR. UDPglucuronosyltransferases. Curr Drug Metab 2000; 1(2):143-161.

24. Wen Z, Martin DE, Bullock P, Lee KH, Smith PC. Glucuronidation of anti-HIV drug candidate bevirimat: identification of human UDP-glucuronosyltransferases and species differences. Drug Metab Dispos 2007; 35(3):440-448.

25. Chen Y, Xie S, Chen S, Zeng S. Glucuronidation of flavonoids by recombinant UGT1A3 and UGT1A9. Biochem Pharmacol 2008; 76(3):416-425.

26. Lewinsky RH, Smith PA, Mackenzie PI. Glucuronidation of bioflavonoids by human UGT1A10: structure-function relationships. Xenobiotica 2005; 35(2):117-129.

27. Uchaipichat V, Mackenzie PI, Elliot DJ, Miners JO. Selectivity of substrate (trifluoperazine) and inhibitor (amitriptyline, androsterone, canrenoic acid, hecogenin, phenylbutazone, quinidine, quinine, and sulfinpyrazone) "probes" for human udp-glucuronosyltransferases. Drug Metab Dispos 2006; 34(3):449-456.

28. Uchaipichat V, Winner LK, Mackenzie PI, Elliot DJ, Williams JA, Miners JO. Quantitative prediction of in vivo inhibitory interactions involving glucuronidated drugs from in vitro data: the effect of fluconazole on zidovudine glucuronidation. Br J Clin Pharmacol 2006; 61(4):427-439.

29. Ghosal A, Hapangama N, Yuan Y, Achanfuo-Yeboah J, Iannucci R, Chowdhury S, Alton K, Patrick JE, Zbaida S. Identification of human UDP-glucuronosyltransferase enzyme(s) responsible for the glucuronidation of posaconazole (Noxafil). Drug Metab Dispos 2004; 32(2):267-271.

30. Caraco Y, Sheller J, Wood AJ. Pharmacogenetic determinants of codeine induction by rifampin: the impact on codeine's respiratory, psychomotor and miotic effects. J Pharmacol Exp Ther 1997, 281(1):330-336.

31. Guillemette, C. Pharmacogenomics of human UDPglucuronosyltransferase enzymes. Pharmacogenomics J 2003; 3(3):136-158

32. Mori A, Maruo Y, Iwai M, Sato H, Takeuchi Y. UDP-glucuronosyltransferase 1A4 polymorphisms in a Japanese population and kinetics of clozapine glucuronidation. Drug Metab Dispos 2005; 33(5):672-675.

33. Jinno H, Saeki M, Saito Y, Tanaka-Kagawa T, Hanioka N, Sai K, Kaniwa N, Ando M, Shirao K, Minami H, Ohtsu A, Yoshida T, Saijo N, Ozawa S, Sawada J. Functional characterization of human UDP-glucuronosyltransferase 1 A9 variant, D256N, found in Japanese cancer patients. J Pharmacol Exp Ther 2003; 306(2):688-693.

34. Iida A, Saito S, Sekine A, Mishima C, Kitamura Y, Kondo K, Harigae S, Osawa S, Nakamura Y. Catalog of 86 single-nucleotide polymorphisms (SNPs) in three uridine diphosphate glycosyltransferase genes: UGT2A1, UGT2B15, and UGT8. J Hum Genet 2002; 47(10):505-510.

35. Kadakol A, Ghosh SS, Sappal BS, Sharma G, Roy Chowdhury J, Roy Chowdhury N. Genetic lesions of bilirubin uridine-diphosphoglucuronate glucuronosyltransferase (UGT1A1) causing Crigler-Najjar and Gilbert syndromes: correlation of genotype to phenotype. Hum Mutat 2000; 16(4): 297-306.

36. Arias IM, Gartner LM, Cohen M, Ezzer JB, Levi AJ. Chronic nonhemolytic unconjugated hyperbilirubinemia with glucuronyl trans- ferase deficiency. Clinical, biochemical, pharmacologic and genetic evidence for heterogeneity. Am J Med 1969; 47(3):395-409.

37. Labrune P, Myara A, Hennion C, Gout JP, Trivin F, Odievre M. Crigler-Najjar type II disease inheritance: a family study. J Inherit Metab Dis 1989; (3):302-306.

38. Ehmer U, Lankisch TO, Erichsen TJ, Kalthoff S, Freiberg N, Wehmeier M, Manns MP, Strassburg CP. Rapid allelic discrimination by TaqMan PCR for the detection of the Gilbert's syndrome marker UGT1A1*28. J Mol Diagn 2008; 10(6):549-552.

39. Matal J, Jancova P, Siller M, Masek V, Anzenbacherova E, Anzenbacher P. Interspecies comparison of the glucuronidation processes in the man, monkey, pig, dog and rat. Neuro Endocrinol Lett 2008; 29(5):738-743.

40. Kaji H, Kume T. Characterization of afloqualone $\mathrm{N}$-glucuronidation: species differences and identification of human UDP-glucuronosyltransferase isoform(s). Drug Metab Dispos 2005; 33(1):60-67.

41. Court MH, Greenblatt DJ. Biochemical basis for deficient paracetamol glucuronidation in cats: an interspecies comparison of enzyme constraint in liver microsomes. J Pharm Pharmacol 1997; 49(4):446-449.

42. Court MH, Greenblatt DJ. Molecular basis for deficient acetaminophen glucuronidation in cats. An interspecies comparison of enzyme kinetics in liver microsomes. Biochem Pharmacol 1997; 53(7):1041-1047.

43. Krishnaswamy S, Duan SX, Von Moltke LL, Greenblatt DJ, Sudmeier JL, Bachovchin WW, Court MH. Serotonin (5-hydroxytryptamine) glucuronidation in vitro: assay development, human liver microsome activities and species differences. Xenobiotica 2003; 33(2):169-180.

44. Habuchi O. Diversity and functions of glycosaminoglycan sulfotransferases. Biochim Biophys Acta 2000; 1474(2):115-127.

45. Senggunprai L, Yoshinari K, Yamazoe Y. Selective role of sulfotransferase 2A1 (SULT2A1) in the N-sulfoconjugation of quinolone drugs in humans. Drug Metab Dispos 2009; 37(8):17111717.

46. Strott CA. Sulfonation and molecular action. Endocr Rev 2002; 23(5):703-732

47. Strassburg CP, Strassburg A, Kneip S, Barut A, Tukey RH, Rodeck B, Manns MP. Developmental aspects of human hepatic drug glucuronidation in young children and adults. Gut 2002; 50(2):259265.

48. Ring JA, Ghabrial H, Ching MS, Smallwood RA, Morgan DJ. Fetal hepatic drug elimination. Pharmacol Ther 1999; 84(3):429-445.

49. Glatt H, Meinl W. Pharmacogenetics of soluble sulfotransferases (SULTs). Naunyn Schmiedebergs Arch Pharmacol 2004; 369(1):55-68.

50. Gamage N, Barnett A, Hempel N, Duggleby RG, Windmill KF, Martin JL, McManus ME. Human sulfotransferases and their role in chemical metabolism. Toxicol Sci 2006; 90(1):5-22.

51. Surh Y-J. Bioactivation of benzylic and allylic alcohols via sulfoconjugation. Chem Biol Interact 1998; 109(1-3):221-235.

52. Lindsay J, Wang LL, Li Y, Zhou SF. Structure, function and polymorphism of human cytosolic sulfotransferases. Curr Drug Metab 2008; 9(2):99-105.

53. Weinshilboum RM, Otterness DM, Aksoy IA, Wood TC, Her C, Raftogianis RB. Sulfation and sulfotransferases 1: Sulfotransferase molecular biology: cDNAs and genes. FASEB J 1997; 11(1):3-14.

54. Falany CN, Xie X, Wang J, Ferrer J, Falany JL. Molecular cloning and expression of novel sulphotransferase-like cDNAs from human and rat brain. Biochem J 2000; 346 Pt 3:857-864.

55. Sakakibara Y, Suiko M, Pai TG, Nakayama T, Takami Y, Katafuchi J, Liu MC. Highly conserved mouse and human brain sulfotransferases: molecular cloning, expression, and functional characterization. Gene 2002; 285(1-2):39-47.

56. Takahashi S, Sakakibara Y, Mishiro E, Kouriki H, Nobe R, Kurogi K, Yasuda S, Liu MC, Suiko M. Molecular cloning, expression and characterization of a novel mouse SULT6 cytosolic sulfotransferase. J Biochem 2009; 146(3):399-405.

57. Dajani R, Hood AM, Coughtrie MW. A single amino acid, glu146, governs the substrate specificity of a human dopamine sulfotransferase, SULT1A3. Mol Pharmacol 1998; 54(6):942-948. 
58. Meinl W, Meerman JH, Glatt H. Differential activation of promutagens by alloenzymes of human sulfotransferase 1A2 expressed in Salmonella typhimurium. Pharmacogenetics 2002; 12(9):677-689.

59. Dajani R, Cleasby A, Neu M, Wonacott AJ, Jhoti H, Hood AM, Modi S, Hersey A, Taskinen J, Cooke RM, Manchee GR, Coughtrie MW. X-ray crystal structure of human dopamine sulfotransferase, SULT1A3. Molecular modeling and quantitative structure-activity relationship analysis demonstrate a molecular basis for sulfotransferase substrate specificity. J Biol Chem 1999; 274(53):37862-37868.

60. Fujita K, Nagata K, Ozawa S, Sasano H, Yamazoe Y. Molecular cloning and characterization of rat ST1B1 and human ST1B2 cDNAs, encoding thyroid hormone sulfotransferases. J Biochem 1997; 122(5):1052-1061.

61. Pai TG, Sugahara T, Suiko M, Sakakibara Y, Xu F, Liu MC. Differential xenoestrogen-sulfating activities of the human cytosolic sulfotransferases: molecular cloning, expression, and purification of human SULT2B1a and SULT2B1b sulfotransferases. Biochim Biophys Acta 2002; 1573(2):165-170.

62. Li X, Clemens DL, Anderson RJ. Sulfation of iodothyronines by human sulfotransferase 1C1 (SULT1C1)*. Biochem Pharmacol 2000; 60(11):1713-1716.

63. Yoshinari K, Nagata K, Shimada M, Yamazoe Y. Molecular characterization of ST1C1-related human sulfotransferase. Carcinogenesis 1998; 19(5):951-953.

64. Falany CN, Krasnykh V, Falany JL. Bacterial expression and characterization of a cDNA for human liver estrogen sulfotransferase. J Steroid Biochem Mol Biol 1995; 52(6):529-539.

65. Comer KA, Falany JL, Falany CN. Cloning and expression of human liver dehydroepiandrosterone sulphotransferase. Biochem $\mathrm{J}$ 1993; 289 ( Pt 1):233-240.

66. Javitt NB, Lee YC, Shimizu C, Fuda H, Strott CA. Cholesterol and hydroxycholesterol sulfotransferases: identification, distinction from dehydroepiandrosterone sulfotransferase, and differential tissue expression. Endocrinology 2001; 142(7):2978-2984.

67. Wang LQ, James MO. Inhibition of sulfotransferases by xenobiotics. Curr Drug Metab 2006; 7(1):83-104.

68. Vietri M, Pietrabissa A, Mosca F, Spisni R, Pacifici GM. Curcumin is a potent inhibitor of phenol sulfotransferase (SULT1A1) in human liver and extrahepatic tissues. Xenobiotica 2003; 33(4):357363.

69. De Santi C, Pietrabissa A, Mosca F, Rane A, Pacifici GM Inhibition of phenol sulfotransferase (SULT1A1) by quercetin in human adult and foetal livers. Xenobiotica 2002; 32(5):363-368.

70. Nishimuta H, Ohtani H, Tsujimoto M, Ogura K, Hiratsuka A, Sawada Y. Inhibitory effects of various beverages on human recombinant sulfotransferase isoforms SULT1A1 and SULT1A3 Biopharm Drug Dispos 2007; 28(9):491-500.

71. King RS, Ghosh AA, Wu J. Inhibition of human phenol and estrogen sulfotransferase by certain non-steroidal anti-inflammatory agents. Curr Drug Metab 2006; 7(7):745-753.

72. Maiti S, Chen X, Chen G. All-trans retinoic acid induction of sulfotransferases. Basic Clin Pharmacol Toxicol 2005; 96(1):44-53.

73. Chen X, Baker SM, Chen G. Methotrexate induction of human sulfotransferases in Hep G2 and Caco-2 cells. J Appl Toxicol 2005; 25(5):354-360.

74. Chen Y, Huang C, Zhou T, Chen G. Genistein induction of human sulfotransferases in HepG2 and Caco-2 cells. Basic Clin Pharmacol Toxicol 2008; 103(6):553-559.

75. Arslan S, Silig Y, Pinarbasi H. An investigation of the relationship between SULT1A1 $\operatorname{Arg}(213)$ His polymorphism and lung cancer susceptibility in a Turkish population. Cell Biochem Funct 2009; 27(4):211-215.

76. Huang SK, Chiu AW, Pu YS, Huang YK, Chung CJ, Tsai HJ, Yang MH, Chen CJ, Hsueh YM. Arsenic methylation capability, myeloperoxidase and sulfotransferase genetic polymorphisms, and the stage and grade of urothelial carcinoma. Urol Int 2009; 82(2):227-234.

77. Bardakci F, Arslan S, Bardakci S, Binatli AO, Budak M Sulfotransferase 1A1 (SULT1A1) polymorphism and susceptibility to primary brain tumors. J Cancer Res Clin Oncol 2008; 134(1):109-114.
78. Tsoi C, Falany CN, Morgenstern R, Swedmark S. Identification of a new subfamily of sulphotransferases: cloning and characterization of canine SULT1D1. Biochem J 2001; 356(Pt 3):891-897.

79. Yoshinari K, Nagata K, Ogino M, Fujita K, Shiraga T, Iwasaki K, Hata T, Yamazoe Y. Molecular cloning and expression of an amine sulfotransferase cDNA: a new gene family of cytosolic sulfotransferases in mammals. J Biochem 1998; 123(3):479-486.

80. Nagata K, Yamazoe Y. Pharmacogenetics of sulfotransferase. Annu Rev Pharmacol Toxicol 2000; 40:159-176.

81. Wang PC, Buu NT, Kuchel O, Genest J. Conjugation patterns of endogenous plasma catecholamines in human and rat. A new specific method for analysis of glucuronide-conjugated catecholamines. J Lab Clin Med 1983; 101(1):141-151.

82. Dunn RT 2nd, Klaassen CD. Tissue-specific expression of rat sulfotransferase messenger RNAs. Drug Metab Dispos 1998; 26(6):598-604.

83. Hein DW, McQueen CA, Grant DM, Goodfellow GH, Kadlubar FF, Weber WW. Pharmacogenetics of the arylamine $\mathrm{N}$-acetyltransferases: a symposium in honor of Wendell W. Weber. Drug Metab Dispos 2000; 28(12):1425-1432.

84. Watanabe M, Sofuni T, Nohmi T. Nohmi. Involvement of Cys69 residue in the catalytic mechanism of N-hydroxyarylamine O-acetyltransferase of Salmonella typhimurium. Sequence similarity at the amino acid level suggests a common catalytic mechanism of acetyltransferase for S. typhimurium and higher organisms. J Biol Chem 1992; 267(12):8429-8436.

85. Payton M, Auty R, Delgoda R, Everett M, Sim E. Cloning and characterization of arylamine $\mathrm{N}$-acetyltransferase genes from Mycobacterium smegmatis and Mycobacterium tuberculosis: increased expression results in isoniazid resistance. J Bacteriol 1999; 181(4):1343-1347.

86. Kawamura A, Graham J, Mushtaq A, Tsiftsoglou SA, Vath GM, Hanna PE, Wagner CR, Sim E. Eukaryotic arylamine $\mathrm{N}$-acetyltransferase. Investigation of substrate specificity by highthroughput screening. Biochem Pharmacol 2005; 69(2):347-359.

87. Grant DM, Blum M, Beer M, Meyer UA. Monomorphic and polymorphic human arylamine $\mathrm{N}$-acetyltransferases: a comparison of liver isozymes and expressed products of two cloned genes. Mol Pharmacol 1991; 39(2):184-191.

88. Kukongviriyapan V, Phromsopha N, Tassaneeyakul W, Kukongviriyapan U, Sripa B, Hahnvajanawong V, Bhudhisawasdi V. Inhibitory effects of polyphenolic compounds on human arylamine N-acetyltransferase 1 and 2. Xenobiotica 2006; 36(1):15-28

89. Chen GW, Chung JG, Hsieh CL, Lin JG. Effects of the garlic components diallyl sulfide and diallyl disulfide on arylamine $\mathrm{N}$-acetyltransferase activity in human colon tumour cells. Food Chem Toxicol 1998; 36(9-10):761-770.

90. Lin JG, Chen GW, Su CC, Hung CF, Yang CC, Lee JH, Chung JG. Effects of garlic components diallyl sulfide and diallyl disulfide on arylamine $\mathrm{N}$-acetyltransferase activity and 2-aminofluorene-DNA adducts in human promyelocytic leukemia cells. Am J Chin Med 2002; 30(2-3):315-325.

91. Butcher NJ, Tetlow NL, Cheung C, Broadhurst GM, Minchin RF. Induction of human arylamine $\mathrm{N}$-acetyltransferase type I by androgens in human prostate cancer cells. Cancer Res 2007; 67(1):8592.

92. Agúndez JA. Polymorphisms of human $\mathrm{N}$-acetyltransferases and cancer risk. Curr Drug Metab 2008; 9(6):520-531.

93. Lammer EJ, Shaw GM, Iovannisci DM, Finnell RH Periconceptional multivitamin intake during early pregnancy, genetic variation of acetyl-N-transferase 1 (NAT1), and risk for orofacial clefts. Birth Defects Res A Clin Mol Teratol 2004; 70(11):846-852.

94. Kawamura A, Westwood I, Wakefield L, Long H, Zhang N, Walters K, Redfield C, Sim E. Mouse N-acetyltransferase type 2, the homologue of human $\mathrm{N}$-acetyltransferase type 1. Biochem Pharmacol 2008; 75(7):1550-1560.

95. Walraven JM, Doll MA, Hein DW. Identification and characterization of functional rat arylamine $\mathrm{N}$-acetyltransferase 3: comparisons with rat arylamine $\mathrm{N}$-acetyltransferases 1 and 2. J Pharmacol Exp Ther 2006; 319(1):369-375.

96. Collins JM. Inter-species differences in drug properties. Chem Biol Interact 2001; 134(3):237-242 
97. Hearse DJ, Weber WW. Multiple N-acetyltransferases and drug metabolism. Tissue distribution, characterization and significance of mammalian N-acetyltransferase. Biochem J 1973; 132(3):519526.

98. van Bladeren PJ. Glutathione conjugation as a bioactivation reaction. Chem Biol Interact 2000; 129(1-2):61-76.

99. Sheehan D, Meade G, Foley VM, Dowd CA. Structure, function and evolution of glutathione transferases: implications for classification of non-mammalian members of an ancient enzyme superfamily. Biochem J 2001; 360(Pt 1):1-16.

100. Soboll S, Grundel S, Harris J, Kolb-Bachofen V, Ketterer B, Sies $H$. The content of glutathione and glutathione S-transferases and the glutathione peroxidase activity in rat liver nuclei determined by a non-aqueous technique of cell fractionation. Biochem J 1995; 311(Pt 3):889-894.

101. Morel F, Rauch C, Petit E, Piton A, Theret N, Coles B, Guillouzo A. Gene and protein characterization of the human glutathione S-transferase kappa and evidence for a peroxisomal localization. J Biol Chem 2004; 279(16):16246-16253.

102. Armstrong RN. Structure, catalytic mechanism, and evolution of the glutathione transferases. Chem Res Toxicol 1997; 10(1):2-18.

103. Hayes JD, Strange RC. Glutathione S-transferase polymorphisms and their biological consequences. Pharmacology 2000; 61(3):154-166

104. Kulkarni AA, Kulkarni AP. Retinoids inhibit mammalian glutathione transferases. Cancer Lett 1995; 91(2):185-189.

105. Ploemen JHTM, Van Ommen B, De Haan A, Venekamp JC, Van Bladeren PJ. Inhibition of human glutathione S-transferases by dopamine, $\alpha$-methyldopa and their 5-S-glutathionyl conjugates. Chem Biol Interact 1994; 90(1):87-99.

106. Liu XP, Goldring CE, Wang HY, Copple IM, Kitteringham NR, Park BK. Extract of Ginkgo biloba induces glutathione-S-transferase subunit-P1 in vitro. Phytomedicine 2009; 16(5):451-455.

107. Williamson G, DuPont MS, Wanigatunga S, Heaney RK, Musk SRR, Fenwick GR, Rhodes MJC. Induction of glutathione S'transferase activity in hepG2 cells by extracts from fruits and vegetables. Food Chem 1997; 60(2):157-160.

108. Hayes JD, Flanagan JU, Jowsey IR. Glutathione transferases. Annu Rev Pharmacol Toxicol 2005; 45:51-88.

109. Iida A, Saito S, Sekine A, Harigae S, Osawa S, Mishima C, Kondo K, Kitamura Y, Nakamura Y. Catalog of 46 single-nucleotide polymorphisms (SNPs) in the microsomal glutathione S-transferase 1 (MGST1) gene. J Hum Genet 2001; 46(10):590-594.

110. Reitz RH, Mendrala AL, Guengerich FP. In vitro metabolism of methylene chloride in human and animal tissues: use in physiologically based pharmacokinetic models. Toxicol Appl Pharmacol 1989; 97(2):230-246.

111. Sherratt PJ, Williams S, Foster J, Kernohan N, Green T, Hayes JD. Direct comparison of the nature of mouse and human GST T1-1 and the implications on dichloromethane carcinogenicity. Toxicol Appl Pharmacol 2002; 179(2):89-97.

112. Igarashi T, Tomihari N, Ohmori S, Ueno K, Kitagawa H, Satoh T. Comparison of glutathione S-transferases in mouse, guinea pig, rabbit and hamster liver cytosol to those in rat liver. Biochem Int 1986; 13(4):641-648.

113. Weinshilboum R. Thiopurine pharmacogenetics: clinical and molecular studies of thiopurine methyltransferase. Drug Metab Dispos 2001; 29(4 Pt 2):601-605.

114. Oselin K, Anier K. Inhibition of human thiopurine S-methyltransferase by various nonsteroidal anti-inflammatory drugs in vitro: a mechanism for possible drug interactions. Drug Metab Dispos 2007; 35(9):1452-1454

115. Fessing MY, Krynetski EY, Zambetti GP, Evans WE. Functional characterization of the human thiopurine S-methyltransferase (TPMT) gene promoter. Eur J Biochem 1998; 256(3):510-517.

116. Otterness DM, Szumlanski CL, Wood TC, Weinshilboum RM. Human thiopurine methyltransferase pharmacogenetics. Kindred with a terminal exon splice junction mutation that results in loss of aktivity. J Clin Invest 1998; 101(5):1036-1044.

117. Klemetsdal B, Wist E, Aarbakke J. Gender difference in red blood cell thiopurine methyltransferase activity. Scand J Clin Lab Invest 1993; 53(7):747-749.
118. McLeod HL, Krynetski EY, Wilimas JA, Evans WE. Higher activity of polymorphic thiopurine S-methyltransferase in erythrocytes from neonates compared to adults. Pharmacogenetics 1995; 5(5):281-286.

119. Szumlanski CL and Weinshilboum RM. Sulphasalazine inhibition of thiopurine methyltransferase: possible mechanism for interaction with 6-mercaptopurine and azathioprine. Br J Clin Pharmacol 1995; 39(4):456-459.

120. Schaeffeler E, Fischer C, Brockmeier D, Wernet D, Moerike K, Eichelbaum M, Zanger UM, Schwab M. Comprehensive analysis of thiopurine S-methyltransferase phenotype-genotype correlation in a large population of German-Caucasians and identification of novel TPMT variants. Pharmacogenetics 2004; 14(7):407-417.

121. Ujiie S, Sasaki T, Mizugaki M, Ishikawa M, Hiratsuka M. Functional characterization of 23 allelic variants of thiopurine S-methyltransferase gene $\left(\right.$ TPMT$\left.^{*} 2-* 24\right)$. Pharmacogenet Genomics 2008; 18(10):887-893.

122. Feng Q, Vannaprasaht S, Peng Y, Angsuthum S, Avihingsanon Y, Yee VC, Tassaneeyakul W, Weinshilboum RM. Thiopurine S-methyltransferase pharmacogenetics: functional characterization of a novel rapidly degraded variant allozyme. Biochem Pharmacol 2010; 79(7):1053-1061.

123. Jones TS, Yang W, EvansWE, Relling MV. Using HapMap Tools in Pharmacogenomic Discovery: The Thiopurine Methyltransferase Polymorphism. Clin Pharmacol Ther 2007; 81(5):729-734.

124. White SD, Rosychuk RA, Outerbridge CA, Fieseler KV, Spier $\mathrm{S}$, Ihrke PJ, Chapman PL. Thiopurine methyltransferase in red blood cells of dogs, cats, and horses. J Vet Intern Med 2000; 14(5):499-502.

125. Wang LN, Zhang L, Nan F, Cheng JQ, Bu H, Liang MZ, Lu YR. HPLC determination and diversity analysis of thiopurine methyltransferase activity in human and pig. Sichuan Da Xue Xue Bao Yi Xue Ban 2006; 37(3):460-463.

126. Shield AJ, Thomae BA, Eckloff BW, Wieben ED, Weinshilboum RM. Human catechol O-methyltransferase genetic variation: gene resequencing and functional characterization of variant allozymes. Mol Psychiatry 2004; 9(2):151-160.

127. Ulmanen I, Peränen J, Tenhunen J, Tilgmann C, Karhunen T, Panula P, Bernasconi L, Aubry J-P, and Lundström K. Expression and intracellular localization of catechol-Omethyltransferase in transfected mammalian cells. Eur J Biochem 1997; 243(12):452-459.

128. Taskinen J, Ethell BT, Pihlavisto P, Hood AM, Burchell B, Coughtrie MW. Conjugation of catechols by recombinant human sulfotransferases, UDP-glucuronosyltransferases, and soluble catechol O-methyltransferase: structure-conjugation relationships and predictive models. Drug Metab Dispos 2003; 31(9):1187-1197.

129. Lehmann L, Jiang L, Wagner J. Soy isoflavones decrease the catechol-O-methyltransferase-mediated inactivation of 4-hydroxyestradiol in cultured MCF-7 cells. Carcinogenesis 2008; 29(2):363-370.

130. Antonini A, Abbruzzese G, Barone P, Bonuccelli U, Lopiano L, Onofrj M, Zappia M, Quattrone8 A. COMT inhibition with tolcapone in the treatment algorithm of patients with Parkinson's disease (PD): relevance for motor and non-motor features. Neuropsychiatr Dis Treat 2008; 4(1):1-9.

131. Lachman HM, Papolos DF, Saito T, Yu YM, Szumlanski CL, Weinshilboum RM. Human catechol-O-methyltransferase pharmacogenetics: Description of a functional polymorphism and its potential application to neuropsychiatric disorders. Pharmacogenetics 1996; 6(3):243-250.

132. Park TW, Yoon KS, Kim JH, Park WY, Hirvonen A, Kang D. Functional catechol-O-methyltransferase gene polymorphism and susceptibility to schizophrenia. Eur Neuropsychopharmacol 2002; 12(4):299-303.

133. Egan MF, Goldberg TE, Kolachana BS, Callicott JH, Mazzanti CM, Straub RE, Goldman D, Weinberger DR. Effect of COMT Val108/158 Met genotype on frontal lobe function and risk for schizophrenia. Proc Natl Acad Sci U S A 2001; 98(12):69176922.

134. Glatt SJ, Faraone SV, Tsuang MT. Association between a functional catechol O-methyltransferase gene polymorphism and 
schizophrenia: meta-analysis of case-control and family-based studies. Am J Psychiatry 2003; 160(3):469-476.

135. Kunugi H, Nanko S, Ueki A, Otsuka E, Hattori M, Hoda F, Vallada HP, Arranz MJ, Collier DA. High and low activity alleles of catechol-O-methyltransferase gene: ethnic difference and possible association with Parkinson's disease. Neurosci Lett 1997; 221(2-3):202-204.

136. Yoritaka A, Hattori N, Yoshino H, Mizuno Y. Catechol-Omethyltransferase genotype and susceptibility to Parkinson's disease in Japan. J Neural Transm 1997; 104(11-12):1313-1317.

137. Tiihonen J, Hallikainen T, Lachman H, Saito T, Volavka J, Kauhanen J, Salonen JT, Ryynänen OP, Koulu M, Karvonen MK, Pohjalainen T, Syvälahti E, Hietala J. Association between the functional variant of the catechol-O-methyltransferase (COMT) gene and type 1 alcoholism. Mol Psychiatry 1999; 4(3):286-289.
138. Kauhanen J, Hallikainen T, Tuomainen TP, Koulu M, Karvonen MK, Salonen JT, Tiihonen J. Association between the functional polymorphism of catechol-O-methyltransferase gene and alcohol consumption among social drinkers. Alcohol Clin Exp Res 2000; 24(2):135-139.

139. Wang T, Franke P, Neidt H, Cichon S, Knapp M, Lichtermann D, Maier W, Propping P, Nöthen MM. Association study of the lowactivity allele of catechol-O-methyltransferase and alcoholism using a family-based approach. Mol Psychiatry 2001; 6(1):109-111.

140. Chen J, Lipska BK, Halim N, Ma QD, Matsumoto M, Melhem S, Kolachana BS, Hyde TM, Herman MM, Apud J, Egan MF, Kleinman JE, Weinberger DR. Functional analysis of genetic variation in catechol-O-methyltransferase (COMT): effects on mRNA, protein, and enzyme activity in postmortem human brain. Am J Hum Genet 2004; 75(5):807-821. 